\section{Sofrimento psíquico entre policiais civis: uma análise sob a ótica de gênero}

\author{
Psychological distress among civilian police: \\ a gender-based analysis
}

\author{
${ }^{1}$ Escola Nacional de Saúde \\ Pública Sergio Arouca, \\ Fundação Oswaldo Cruz, \\ Rio de Janeiro, Brasil. \\ Correspondência \\ E. R. Souza \\ Centro Latino-Americano \\ de Estudos de Violência e \\ Saúde, Escola Nacional de \\ Saúde Pública Sergio Arouca, \\ Fundação Oswaldo Cruz. \\ Av. Brasil 4036, sala 700, \\ Rio de Janeiro, $R J$ \\ 21040-361, Brasil. \\ edinilsa@claves.fiocruz.br
}

\begin{abstract}
This study aimed to investigate potential psychological distress among members of the civilian police force, based on gender differences. It analyzes data from previous research on work, health conditions, and quality of life in the civilian police using both quantitative and qualitative methods. The study included and tested data from the questionnaire applied to a statistically representative sample of 2,746 civilian police (80.8\% males and $19.2 \%$ females) from the city of Rio de Janeiro, Brazil, according to gender variables and position in the police force (administrative, technical, and operational law enforcement). The study presents an overview of social and economic characteristics, job conditions, health problems, and quality of life, highlighting the areas of information where gender appears as an important factor. The Self-Reported Questionnaire (SRQ-20) was used to investigate psychological distress comparing males and females. The results did not show gender differences in psychological distress, but did identify significant differences in some items in the scale. Female police, especially in technical positions, showed a higher proportion than males. The conclusions corroborate some previous research.
\end{abstract}

Gender Identity; Psychological Stress; Police

\author{
Edinilsa Ramos de Souza 1 \\ Letícia Gastão Franco 1 \\ Camila de Carvalho Meireles 1 \\ Vanessa Tokunaga Ferreira 1 \\ Nilton César dos Santos 1
}

\section{Introdução}

O presente artigo tem como objetivo investigar o sofrimento psíquico de policiais civis, sob a ótica de gênero. Visa a suprir a lacuna de estudos no país que tratam dos efeitos das condições de trabalho na saúde dos policiais, sobretudo referentes à distinção entre gêneros na instituição policial.

A partir da década de 80 constatou-se no Brasil um aumento dos índices de violência expresso nos indicadores do setor saúde e da segurança pública. O Estado e a capital do Rio de Janeiro são considerados como dos mais violentos do país.

Essa intensificação da violência tem exigido políticas mais eficazes de segurança pública e acarretado uma sobrecarga física e emocional para os trabalhadores desse setor. Além de lidar com as pressões da sociedade por um policiamento eficiente, na realidade brasileira as precárias condições de trabalho interferem no desempenho desses profissionais, afetam sua saúde, geram desgaste, insatisfação e provocam estresse e sofrimento psíquico 1,2,3. Estudos destacam que o policial lida com riscos reais e imaginários que são inerentes à profissão, que geram estresse e sofrimento 4,5 , e mesmo quando imaginários podem desencadear respostas de alerta e levar à morte 4,6 .

Neste trabalho tomam-se as idéias de Dejours 7 de que o sofrimento humano é inerente ao processo laboral, devendo-se compreender 
suas causas para modificá-lo e reorganizar o processo de trabalho, e os estudos que privilegiam a relação entre estresse e trabalho ressaltam a importância e centralidade do trabalho na vida dos trabalhadores, ora favorecendo a saúde ora a doença. Nessa linha de pensamento o descompasso entre a organização do trabalho prescrito e a organização do trabalho real favorece o aparecimento de sofrimento mental, uma vez que os trabalhadores são obrigados a transgredir para realizarem a tarefa laboral. A rigidez organizacional impede a atividade criativa e a elaboração das causas do sofrimento, podendo gerar intensa angústia. A desadaptação ao trabalho pode ser vivida tanto física quanto psiquicamente. Ao contrário, o trabalho saudável seria aquele que permite o desenvolvimento do indivíduo, alternando exigências e período de repouso com o controle do trabalhador sobre o processo de trabalho.

O sofrimento psíquico é aqui considerado sob o ponto de vista do estresse a que esses profissionais são submetidos em seu trabalho. Estresse é entendido como o desequilíbrio entre as demandas do trabalho e a capacidade de resposta dos trabalhadores 3,8. Fatores estressores como alta demanda, baixo controle sobre o processo de trabalho, freqüente contato com o público, longas jornadas de trabalho, recursos materiais insuficientes, insatisfação com a atividade e a remuneração, dificuldade de ascenção profissional 2,3,5,9,10, além da exposição ao sofrimento alheio, a situações perigosas e a problemas familiares, estariam relacionados ao sofrimento ou distúrbios psíquicos.

Fernandes et al. 11 investigando agentes penitenciários da Região Metropolitana de Salvador, Bahia, destacam que esses agentes e os policiais são profissionais submetidos a alto risco e prevalência de estresse debilitante, ansiedade e abuso de álcool.

Mesmo tendo evoluído a participação feminina na Polícia, as atividades inerentes ao trabalho policial ainda são consideradas masculinas. Minayo \& Souza ${ }^{1}$ destacaram que a visão machista predominante na corporação é responsável por parte dos conflitos existentes entre os pares: os homens têm dificuldade de se submeterem às ordens das mulheres.

Segundo Rocha \& Debert-Ribeiro ${ }^{12}$, são recentes no Brasil estudos sobre a saúde da mulher que abordem a relação entre gênero e trabalho, e busquem compreender como as relações sociais de gênero interferem nas relações de trabalho e afetam a saúde da trabalhadora.

Diferentemente do sexo, gênero é entendido neste trabalho como uma categoria sóciocultural e historicamente construída e, por isso, variável de acordo com as diferentes sociedades e épocas. Alguns autores 13,14,15 analisam essa construção social do gênero a partir das características psíquicas, sócio-históricas e políticas. Para Santos 16, gênero são as atitudes que vão indicar se a pessoa é homem ou mulher, e a cultura vai designar o que é próprio do universo simbólico feminino e masculino. Ceccheto 17 , analisando o gênero masculino, concorda com Connel 18 ao afirmar que gênero são formas de estruturação de práticas e se engendra no plano dos atributos culturais. Cruza-se com uma rede de elementos vinculados às estruturas de classe, poder e etnicidade que fundamentam as relações sociais. Para Connel 18, a construção dessa categoria passa por configurações específicas constituídas em situações particulares e mutáveis.

Assim, a questão de gênero promove uma ruptura com a abordagem biologicista e perpassa a divisão ocupacional e sexual do trabalho, principalmente em instituições marcadas por uma visão machista, como é a polícia. $\mathrm{O}$ fato da mulher trabalhar fora e ocupar determinados cargos ditos masculinos pode ser representado e interpretado como uma transgressão às regras sociais estabelecidas em relação ao papel do gênero feminino.

Santos 16 chama a atenção também para o paradoxo imposto às mulheres: a sobreposição da imagem da mulher responsável pelo lar sobre a imagem da mulher trabalhadora. Exige-se delas o trabalho extradoméstico e as condenam pelo "abandono" do lar. Essas cobranças, somadas ao conflito de papéis e funções no trabalho, criam tensões que podem resultar em sofrimento psíquico, como bem destacam Vermeulen \& Mustard 19. Por outro lado, esses últimos admitem que a maior participação da mulher na força de trabalho não tem efeito adverso, mas eleva a saúde: donas-de-casa experimentam mais sintomas depressivos do que mulheres casadas empregadas. Eles sugerem que o conflito família-trabalho é mais importante para a qualidade da vida profissional entre as mulheres do que entre os homens.

Entretanto, as investigações que buscaram identificar diferenças de gênero na relação entre sofrimento psíquico e trabalho não são conclusivas. Alguns estudos observaram a existência de diferenças 20,21,22,23, outros as negam. Os autores consideram que tais inconsistências devem-se aos diferentes desenhos dos estudos e às distintas ênfases dadas aos fatores investigados e medidas usadas para verificá-los.

Portanto, investigar como se expressa o sofrimento psíquico entre policiais civis do Rio de Janeiro, sob a ótica do gênero, é o objetivo deste estudo. 


\section{Metodologia}

Os dados usados neste artigo provêm de uma pesquisa mais ampla cujo objetivo foi investigar as condições de trabalho, de saúde e a qualidade de vida de policiais civis da cidade do Rio de Janeiro 1. O estudo anterior usou metodologia quantitativa (aplicação de questionário a uma amostra estatisticamente representativa de 2.746 policiais) e qualitativa (12 entrevistas e 7 grupos focais envolvendo 51 policiais dos diversos estratos e cargos). O presente artigo tem por objetivo investigar diferenças de gênero na experiência de sofrimento psíquico por esses trabalhadores.

A análise subdividiu os policiais em três estratos, segundo a organização de suas atividades de trabalho: administrativo (ADM), técnico (TEC) e operacional (OP). O setor administrativo constitui o suporte que dá as condições para as atividades-fim, isto é, a produção da investigação policial, e por isso, é designado como um conjunto de atividades-meio. O técnico tem como principal atividade a produção de laudos e perícias científicas para apoiar a investigação policial. Já o operacional é responsável pela produção de registros de crimes e acidentes de trânsito e pela investigação de autoria de delitos que são concretizados pelo registro de ocorrência e de inquérito policial, sendo sua atividade denominada atividade-fim, tendo, portanto, papel central na produção social da polícia civil.

O questionário continha 124 questões com 482 itens distribuídos em quatro blocos de questões versando sobre (i) características sócio-econômicas; (ii) condições de trabalho; (iii) condições de saúde do policial e (iv) qualidade de vida. Para o presente trabalho foram analisadas 76 questões que se referiam: às características sócio-econômicas (17), à qualidade de vida (33), às condições de trabalho (20) e apenas seis questões relativas às condições de saúde do policial civil porque apresentavam relação direta com as doenças comumente consideradas psicossomáticas (colesterol, pressão sanguínea, doenças do aparelho respiratório, do sistema digestivo e do sistema nervoso, além de problemas musculares, ósseos e de pele). Entre as questões sobre qualidade de vida foi analisada a Escala de Apoio Social ${ }^{1}$ validada no Brasil por Chor et al. ${ }^{24}$. Todas essas questões foram analisadas descritivamente segundo variáveis de sexo e estrato policial, e testadas usando o $\chi^{2}$ com grau de $95 \%$ de confiança, a fim de identificar diferenças estatísticas.

Para avaliar a existência de sofrimento psíquico ou distúrbios psiquiátricos menores, foram analisados os dados relativos à escala Self-Reported Questionaire (SRQ-20). Esse instrumento originalmente possuía 24 perguntas: 20 referentes a distúrbios não-psicóticos e 4 sobre distúrbios psicóticos. Várias versões do SRQ surgiram em diversas línguas, inclusive no Brasil 25,26,27,28,29, e demonstraram bons índices de confiabilidade e validade da escala: entre $73 \%$ e $93 \%$ para sensibilidade, entre $72 \%$ a $89 \%$ para especificidade; e a taxa de erros de classificação ficou entre 18\% e $24 \%$. A versão aplicada no Brasil foi validada por Mari \& Williams 30, que observaram sensibilidade de $83 \%$, especificidade de $80 \%$ e $19 \%$ de erros de classificação Ela se refere a transtornos de elevada prevalência em nível populacional que costumam estar relacionados, indiretamente, às condições sócio-econômicas e, mais diretamente, aos eventos de vida estressantes 31,32,33. Essa escala não permite classificar distúrbios psiquiátricos específicos ou seus níveis de intensidade, mas apenas detectar a existência ou não de sofrimento.

A escala usada na referida pesquisa possui vinte itens medindo sofrimento psíquico (distúrbios não-psicóticos). O ponto de corte proposto para a escala é de 7 para homem e 8 para mulher. Cada resposta positiva equivale a um ponto.

As comparações foram feitas entre os três estratos, mas também dois-a-dois, e finalmente foram comparadas as diferenças de gênero no interior de cada estrato. Por motivo de espaço, os resultados aqui apresentados mostram apenas os itens onde foram encontradas diferenças significativas, ressaltando-se com sombreamento as caselas onde a diferença entre os gêneros são maiores.

Os dados são apresentados em tabelas, buscando dar uma visão dos principais achados em relação ao perfil sócio-econômico dos policiais, às condições de trabalho, de saúde e de qualidade de vida destes. Finalmente, se apresenta a análise do SRQ-20 em função das diferenças de gênero observadas.

\section{Resultados}

Quanto ao perfil sócio-econômico observa-se que a maioria dos policiais é do sexo masculino. As mulheres representam $15 \%$ do estrato Operacional, $36 \%$ do Técnico e $18 \%$ do Administrativo.

Nos três setores a maioria dos policiais está na faixa dos 36 aos 45 anos de idade. A maior parte deles é casada, mas, comparando com os homens, o percentual de mulheres solteiras, separadas e viúvas é maior. O percentual de mulheres que possuem casa própria quitada também é maior que o de homens.

No estrato Operacional existem mais mulheres $(21,3 \%)$ que homens $(11,1 \%)$ com idade até 35 anos. E é mais de três vezes maior a proporção de 
homens (23,1\% versus $5 \%$ de mulheres) com 51 anos ou mais.

No estrato Técnico a distribuição etária é mais semelhante entre os gêneros. Existem 15,9\% de mulheres e $12,7 \%$ de homens com até 35 anos de idade e $27,3 \%$ mulheres contra $26,8 \%$ homens com 51 anos ou mais.

No estrato Administrativo, existem mais mulheres $(10,3 \%)$ que homens $(3,7 \%)$ com até 35 anos e o dobro (30,8\%) de homens em relação a mulheres $(15,4 \%)$ com 51 anos ou mais.

Em relação às condições de trabalho observaram-se diferenças de gênero no que se refere a algumas questões. Para o conjunto dos dados as mulheres afirmam que têm tirado mais férias que os homens e viajam mais nas folgas. As dos estratos Operacional e Técnico costumam aproveitar as folgas para ir ao cinema. A maioria das mulheres dos setores Operacional e Administrativo relata ficar mais sozinhas nas folgas.

Os homens dos três estratos vão mais a clubes e praticam esportes. Também nos três estratos, eles referem fazer mais plantão e exercerem outra atividade remunerada além da polícia. Entre as mulheres, as do setor técnico exercem mais outras atividades remuneradas que as dos outros estratos.

As mulheres do setor Técnico informam ter feito mais cursos de especialização e pós-graduação que os homens, enquanto as do Operacional relatam ter feito mais cursos de informática.

Os homens, mais que as mulheres, percebem que há riscos na atividade atual e que suas famílias também correm riscos. Já as mulheres dos três estratos tendem a perceber que não correm riscos ou que eles existem apenas eventualmente. O risco mais percebido por elas é o de virem a sofrer violência sexual.

Na Tabela 1 encontram-se os dados referentes às questões de saúde. Embora o percentual de mulheres do estrato Operacional tenha afirmado mais que os homens que consideram seu estado de saúde bom, no conjunto dos estratos apresentam mais problemas de saúde que os homens. As mulheres dos estratos Técnico e Administrativo informam possuir mais que os homens

Tabela 1

Fatores referentes à saúde dos Policiais Civis do Rio de Janeiro, Brasil, nos três estratos comparados por gênero.

\begin{tabular}{|c|c|c|c|c|c|c|}
\hline \multirow[b]{2}{*}{ Itens sobre saúde } & \multicolumn{2}{|c|}{ Operacional (\%) } & \multicolumn{2}{|c|}{ Técnico (\%) } & \multicolumn{2}{|c|}{ Administrativo (\%) } \\
\hline & Homens & Mulheres & Homens & Mulheres & Homens & Mulheres \\
\hline \multicolumn{7}{|c|}{ Como considera seu estado de saúde } \\
\hline Bom & 50,9 & 58,7 & * & * & * & * \\
\hline Regular & 23,3 & 9,3 & * & * & * & * \\
\hline \multicolumn{7}{|l|}{ Colesterol alto } \\
\hline Sim & * & * & * & * & 33,1 & 14,1 \\
\hline \multicolumn{7}{|l|}{ Pressão alta } \\
\hline Sim, 1 vez & 14,3 & 10,9 & 23,7 & 13,3 & 11,4 & 3,9 \\
\hline Nunca & 59,0 & 67,8 & 59,2 & 70,7 & 57,4 & 74,0 \\
\hline \multicolumn{7}{|l|}{ Rinite alérgica } \\
\hline $\operatorname{Sim}$ & * & * & 20,5 & 36,7 & 20,5 & 39,7 \\
\hline \multicolumn{7}{|c|}{ Constipação intestinal } \\
\hline Sim & 9,1 & 22,5 & * & * & 7,6 & 26,9 \\
\hline \multicolumn{7}{|c|}{ Problemas de ossos e cartilagens } \\
\hline Sim & * & * & 6,8 & 12,4 & 8,7 & 16,7 \\
\hline \multicolumn{7}{|c|}{ Bócio ou problemas de tireóide } \\
\hline Sim & * & * & 0,3 & 6,8 & * & * \\
\hline \multicolumn{7}{|l|}{ Anemia } \\
\hline $\operatorname{Sim}$ & * & * & 2,6 & 16,9 & * & * \\
\hline \multicolumn{7}{|c|}{ Dores de cabeça e enxaquecas } \\
\hline Sim & * & * & 18,8 & 36,2 & 19,4 & 37,2 \\
\hline
\end{tabular}

* Não significativo. 
rinite alérgica, problemas de ossos e cartilagem, dores de cabeça e enxaquecas. Já as mulheres dos estratos Operacional e Administrativo referem mais constipação intestinal que os homens. As mulheres do estrato Técnico apresentam maiores proporções de bócio ou problemas de tireóide e anemia. Os homens do Operacional relataram mais que as mulheres que seu estado de saúde é regular e, nos três estratos, referem mais pressão alta.

Quanto à qualidade de vida, pode-se dizer que as mulheres possuem uma visão mais pessimista. Conforme a Tabela 2, elas sentem-se mais insatisfeitas com a vida sexual (OP) e afetiva (OP/ TEC/ADM), a felicidade dos familiares (ADM) e consideram mais que os homens que sua vida pessoal será igual ou pior no futuro (TEC).

Minayo \& Souza 1 encontraram para o conjunto dos policiais civis menos apoio social entre o pessoal do estrato administrativo. Entretanto, ao analisar a variável gênero, no interior de cada estrato, observa-se que as mulheres, sobretudo do estrato operacional, tendem a ter menos apoio social, afirmando que contam apenas às vezes ou nunca contam com alguém para se divertir (OP/TEC); nunca contam com alguém para relaxar (TEC); raramente contam com alguém que amam (OP/TEC); raramente ou nunca contam com alguém para ajudar nas tarefas de casa quando ficam doentes (OP/ADM); raramente ou nunca contam com alguém para o preparo das re- feições (TEC/ADM); nunca contam com alguém para distrair a cabeça $(\mathrm{OP})$; às vezes contam com alguém para compartilhar preocupações e medos (OP). Finalmente, referem que nunca podem contar muito com alguém para poder fazer coisas agradáveis $(\mathrm{OP})$ e nunca contam com alguém para levá-las ao médico (OP) (Tabela 3).

Considerando-se as dimensões da escala, em função dos itens acima em que foram observadas diferenças significativas entre os gêneros, parece que as policiais do estrato operacional têm menos apoio na dimensão de interação social, enquanto as do estrato administrativo têm menos apoio na dimensão material. Já as policiais técnicas relataram menos apoio em um item de cada uma das dimensões afetiva, material e de interação social positiva.

Os policiais homens relatam, mais que suas colegas de trabalho, que nunca contam com alguém para relaxar e para se distrair, ambos itens da dimensão de interação social positiva.

Com relação ao sofrimento psíquico não foram observadas diferenças significativas entre os gêneros. No entanto, como se pode ver na Tabela 4, do total de 20 itens do SRQ-20 foram encontradas diferenças de gênero em 10 deles. Essas distinções indicam que os homens do estrato Operacional apresentam maior proporção de falta de apetite em relação às mulheres, e os do estrato Técnico aparecem com maior proporção de sentimento de inutilidade. As mulheres

Tabela 2

Fatores referentes à qualidade de vida dos Policiais Civis do Rio de Janeiro, Brasil, nos três estratos comparados por gênero.

\begin{tabular}{|c|c|c|c|c|c|c|}
\hline \multirow[b]{2}{*}{ Itens sobre qualidade de vida } & \multicolumn{2}{|c|}{ Operacional (\%) } & \multicolumn{2}{|c|}{ Técnico (\%) } & \multicolumn{2}{|c|}{ Administrativo (\%) } \\
\hline & Homens & Mulheres & Homens & Mulheres & Homens & Mulheres \\
\hline \multicolumn{7}{|l|}{ Vida social } \\
\hline Insatisfeito & 9,8 & 26,0 & * & * & * & * \\
\hline \multicolumn{7}{|l|}{ Vida afetiva } \\
\hline Muito satisfeito & 40,3 & 28,6 & 38,7 & 30,3 & 40,6 & 23,7 \\
\hline Insatisfeito & 4,5 & 13,0 & 4,6 & 16,0 & 4,0 & 6,6 \\
\hline Muito insatisfeito & 2,7 & 2,6 & 2,3 & 3,4 & 0,6 & 9,2 \\
\hline \multicolumn{7}{|l|}{ Felicidade dos familiares } \\
\hline Insatisfeito & * & * & * & * & 5,2 & 13,0 \\
\hline \multicolumn{7}{|l|}{ Planos para vida familiar } \\
\hline Sempre faz & * & * & 64,9 & 49,1 & * & * \\
\hline \multicolumn{7}{|l|}{ Vida pessoal no futuro } \\
\hline Melhor & * & * & 75,2 & 68,2 & * & * \\
\hline Igual & * & * & 20,5 & 30,6 & * & * \\
\hline Pior & * & * & 1,2 & 4,4 & * & * \\
\hline
\end{tabular}

* Não significativo. 
Itens referentes ao apoio social recebido pelos Policiais Civis do Rio de Janeiro, Brasil, nos três estratos comparados por gênero.

\begin{tabular}{|c|c|c|c|c|c|c|}
\hline \multirow[b]{2}{*}{ Itens da escala de apoio social } & \multicolumn{2}{|c|}{ Operacional (\%) } & \multicolumn{2}{|c|}{ Técnico (\%) } & \multicolumn{2}{|c|}{ Administrativo (\%) } \\
\hline & Homens & Mulheres & Homens & Mulheres & Homens & Mulheres \\
\hline \multicolumn{7}{|l|}{ Conta com alguém para se divertir } \\
\hline Sempre & 59,8 & 42,9 & 59,7 & 46,5 & * & * \\
\hline Às vezes & 9,7 & 19,5 & 10,8 & 21,5 & * & * \\
\hline Nunca & 1,3 & 6,5 & 2,7 & 2,3 & & \\
\hline \multicolumn{7}{|l|}{ Conta com alguém para relaxar } \\
\hline Sempre & 55,5 & 40,5 & 54,6 & 48,5 & * & * \\
\hline Nunca & 9,5 & 1,6 & 3,1 & 4,1 & * & * \\
\hline Raramente & 6,5 & 5,4 & 3,2 & 11,1 & * & * \\
\hline \multicolumn{7}{|l|}{ Conta com alguém que você ame } \\
\hline Sempre & 68,5 & 52,6 & 64,5 & 55,0 & * & * \\
\hline Raramente & 3,4 & 7,9 & 3,4 & 9,4 & * & * \\
\hline Nunca & 1,8 & 5,3 & 4,4 & 2,3 & & \\
\hline \multirow{2}{*}{\multicolumn{7}{|c|}{$\begin{array}{l}\text { Conta com alguém para ajudá-lo em } \\
\text { casa quando está doente }\end{array}$}} \\
\hline & & & & & & \\
\hline Sempre & 61,0 & 46,1 & * & * & 56,1 & 32,5 \\
\hline Raramente & 7,2 & 15,8 & * & * & 8,7 & 10,4 \\
\hline Nunca & 3,4 & 6,6 & * & * & 2,3 & 6,5 \\
\hline \multicolumn{7}{|c|}{ Conta com alguém para preparar refeição } \\
\hline Sempre & 69,7 & 48,7 & 66,4 & 49,7 & 65,8 & 30,3 \\
\hline Raramente & 4,3 & 10,5 & 3,1 & 7,6 & 4,3 & 18,4 \\
\hline Nunca & 22,0 & 10,5 & 2,4 & 4,1 & 0,3 & 3,9 \\
\hline \multicolumn{7}{|l|}{ Conta com alguém para se distrair } \\
\hline Sempre & 49,3 & 30,7 & * & * & 45,1 & 26,3 \\
\hline Nunca & 2,4 & 8,0 & * & * & 2,3 & 1,3 \\
\hline \multicolumn{7}{|c|}{ Conta com alguém para compartilhar preocupações } \\
\hline Sempre & 44,8 & 35,5 & * & * & * & * \\
\hline Às vezes & 14,4 & 27,6 & * & * & * & * \\
\hline \multicolumn{7}{|c|}{ Conta com alguém para levá-lo ao médico } \\
\hline Raramente & 12,2 & 6,5 & * & * & * & * \\
\hline Nunca & 4,3 & 11,7 & * & * & * & * \\
\hline \multicolumn{7}{|c|}{ Conta com alguém para fazer coisas agradáveis } \\
\hline Sempre & 57,0 & 40,0 & * & * & * & * \\
\hline Nunca & 0,9 & 4,0 & * & * & * & * \\
\hline
\end{tabular}

* Não significativo.

dos três setores têm maiores freqüências de dor de cabeça que os homens. As dos setores Operacional e Técnico mostram elevadas proporções de choro e sensação de cansaço. As mulheres do estrato Técnico relatam grandes freqüências em relação aos homens quanto a dormir mal, assustar-se com facilidade, sentirem-se nervosas, tensas ou agitadas, sentirem-se tristes e terem perdido o interesse pelas coisas.

Convém destacar que na pesquisa original 1 $20,2 \%$ dos policiais civis do Rio de Janeiro, inde- pendente do sexo, apresentaram sofrimento psíquico a partir do SRQ-20. Analisados em relação ao tempo de trabalho, observou-se sofrimento psíquico em 13,2\% dos que estão há dez anos na corporação; em $24 \%$ dos que estão de 11 a 20 anos e em $16,2 \%$ dos que têm mais de vinte anos na polícia, sugerindo um efeito de sobrevivência. Ao analisar sofrimento mental segundo a organização do trabalho, o estudo acima encontrou que o grupo dos policiais lotados nas delegacias (os operacionais) são os mais atingidos com $22,1 \%$; 
Fatores relacionados ao sofrimento psíquico (SRQ-20) dos Policiais Civis do Rio de Janeiro, Brasil, nos três estratos comparados por gênero.

\begin{tabular}{|c|c|c|c|c|c|c|}
\hline \multirow[b]{2}{*}{ Itens do SRQ-20 } & \multicolumn{2}{|c|}{ Operacional (\%) } & \multicolumn{2}{|c|}{ Técnico (\%) } & \multicolumn{2}{|c|}{ Administrativo (\%) } \\
\hline & Homens & Mulheres & Homens & Mulheres & Homens & Mulheres \\
\hline Falta de apetite & 10,4 & 1,3 & * & * & * & * \\
\hline Sente-se inútil & * & * & 6,9 & 2,9 & * & * \\
\hline Tem dores de cabeça & 24,6 & 36,0 & 16,9 & 32,4 & 17,3 & 39,5 \\
\hline Tem chorado mais que de costume & 9,3 & 22,7 & 5,2 & 17,3 & * & * \\
\hline Dorme mal & * & 24,1 & 37,4 & * & * & * \\
\hline Assusta-se com facilidade & * & 12,8 & 33,5 & * & * & * \\
\hline Sente-se nervoso, tenso ou agitado & * & 35,7 & 46,5 & * & * & * \\
\hline Sente-se triste & * & 20,6 & 32,9 & * & * & * \\
\hline Perde o interesse pelas coisas & * & 11,0 & 19,1 & * & * & * \\
\hline Sente-se cansado & 24,7 & 40,0 & 14,5 & 23,1 & * & * \\
\hline
\end{tabular}

* Não significativo.

os que se encontram lotados no setor administrativo vêm em segundo lugar com 19,5\% e por último aparecem os policiais do setor técnico com $15,1 \%$.

\section{Discussão}

Antes de iniciar a discussão sobre os achados é preciso referir que uma limitação deste trabalho é o seu desenho, pois trata-se de um estudo transversal que não permite o estabelecimento de nexos causais. Entretanto, os dados aqui analisados permitem fazer algumas ponderações.

Primeiramente viu-se que o percentual de mulheres solteiras, separadas e viúvas é maior que o de homens, podendo-se, a partir disso, levantar a hipótese de que elas sejam mais sozinhas. Tal hipótese poderia explicar o fato de sua visão mais pessimista com relação à vida sexual e afetiva, assim como à sua vida familiar e futura. Outra questão importante é o fato delas relatarem ter menos apoio social, podendo contar menos com as pessoas, o que poderia aumentar a carga psíquica sobre elas. Esse dado parece ser reforçado pela percepção de mais problemas de saúde pelas mulheres, uma vez que tem sido demonstrado que pessoas que têm mais apoio social tendem a ter menos problemas de saúde 34 . O baixo apoio social aqui observado entre as mulheres contradiz a afirmação de Fuhrer 21 de que a mulher dá e recebe mais apoio social que os homens. Em seu estudo, esse autor defende que embora apoio social seja identificado como um fator protetor para a saúde mental, as mulheres apresentaram maiores proporções e maior número de itens de sofrimento psíquico que os homens.
Além do apoio social, as pressões culturais que as responsabilizam pelo cuidado com o lar e com a família além de sua carga laboral, podem ser fatores predisponentes para o sofrimento psíquico. Mas, de acordo com Vermeulen \& Mustard 19, o baixo apoio social, associado às pressões no trabalho, geram aumento de angústia psíquica tanto nos homens quanto nas mulheres.

O presente estudo encontrou que apesar das policiais mulheres tirarem mais férias, viajarem mais e irem a cinemas nas folgas, cogita-se que essas atividades podem ser realizadas sozinhas, o que pode reforçar a suposição da solidão como agravante do sofrimento psíquico. Os homens demonstraram estar envolvidos, em grande parte, com atividades em grupo (em clubes ou praticando esportes). Esse dado parece confirmar a tese de Fuhrer 21 de que as mulheres têm um maior número de pessoas próximas a elas, enquanto os homens têm maior rede social.

A hipótese de que os homens poderiam expressar sofrimento psíquico através de seu corpo, somatizando alguns problemas de saúde, não foi confirmada neste estudo. Embora eles tenham relatado uma preocupação bastante superior à das mulheres com relação aos riscos da profissão, elas apresentaram mais queixas de doenças. Segundo Bergl et al. 22, as mulheres apresentam menos estresse, porém os percebem como mais severos que os homens. Uma pesquisa com analistas de sistema em duas empresas de processamento de dados da região metropolitana de São Paulo 12, constatou que entre as mulheres é freqüente a insatisfação com o trabalho e há maior prevalência de estresse em relação à irritabilidade, ansiedade, atenção instável e depressão. 
Alguns autores defendem a idéia de que a percepção de situações estressantes e sofrimento psíquico depende de características de personalidade do sujeito. Assim, policiais com personalidade introvertida, ainda que vivam menos situações estressantes no trabalho, tendem a ver tais situações como mais estressantes que policiais com personalidade extrovertida.

Estudo realizado por Santana (1993, apud Fernandes et al. 11) com agentes penitenciários também destacou o gênero como variável determinante para o estresse. Ressalta que, talvez por questões culturais, as mulheres sejam mais sujeitas às tensões no trabalho por reagirem menos a essas tensões. $\mathrm{O}$ autor enfatiza ainda o desgaste da mulher para manter a autoridade exigida no exercício da função, além daquele decorrente do acúmulo do trabalho doméstico. Essa tensão relativa à manutenção da autoridade por parte das mulheres no interior da corporação policial é inegável.

Em um estudo realizado por Scott (1992, apud Calais et al. 20) com administradores escolares, as mulheres se apresentaram mais estressadas que os homens, talvez por serem mais aptas a lamentarem e expressarem seus sentimentos e se envolverem mais com a vida de outras pessoas. Esses estudiosos lembram que alguns pesquisadores enfocam a diferença entre os sexos do ponto de vista biológico, afirmando que as variações hormonais também seriam responsáveis pelo aumento do estresse entre as mulheres. Sua hipótese é que o nível de estresse estaria aumentando nas mulheres pela sobrecarga de exigências profissionais e pessoais, biológicas, hormonais, sexuais e sociais.

No presente estudo destaca-se a extrema relevância das mulheres do estrato técnico. Nele foram verificadas as maiores diferenças de gênero no que se refere a itens do SRQ-20. Dentre as nove questões em que foram observadas distinções entre homens e mulheres especificamente nesse estrato, elas apresentaram percentual significativamente maior que os homens em oito quesitos, sendo eles: dor de cabeça, chorar mais que de costume, dormir mal, assustar-se com facilidade, sentir-se nervoso, tenso ou agitado, sentir-se triste, perder o interesse pelas coisas e sentir-se cansado. É também nesse estrato que se encontra a maior representação de policiais mulheres. Além disso, as policiais técnicas, se comparadas com as dos outros dois estratos, exercem mais outras atividades remuneradas fora da polícia, tendo maior carga de trabalho, o que pode ser um fator importante para o aumento do sofrimento psíquico. A isso, soma-se ainda o fato delas serem mais velhas que as mulheres dos demais estratos.
Outra peculiaridade das policiais técnicas é o fato delas terem mais cursos de especialização, pós-graduação e estudarem direito e legislação mais que os homens. Esse maior nível de formação pode ser responsável por uma percepção diferenciada de sua qualidade de vida e trabalho, elevando seu nível de sofrimento psíquico.

Vermeulen \& Mustard 19 encontraram em seu estudo que as mulheres responderam com mais freqüência a existência de condições psicossociais negativas no trabalho.

Os dados aqui encontrados são corroborados por outras pesquisas que abordam a questão de gênero. Moraes et al. 35, em investigação com os policiais militares do Estado de Minas Gerais, destacam a necessidade das mulheres se esforçarem mais para conseguirem o mesmo reconhecimento profissional que o homem, o que as tornaria mais propensas ao estresse, principalmente pelo fato da Polícia Militar ser uma instituição predominantemente masculina. Além disso, assumem características do universo simbólico masculino para ocuparem tal cargo. Esse esforço gera ainda mais desgastes físicos e psíquicos pelo fato de continuarem a ser associadas ao papel de responsáveis pelo lar e pela família. Essa mesma pesquisa ressalta ainda a desqualificação e o empobrecimento do trabalho feminino (menores salários e dupla jornada de trabalho) como resultado da manutenção da hierarquia social que outorga a supremacia masculina no mercado de trabalho.

É mister ressaltar que as diferenças observadas entre os gêneros nos itens isolados que investigam sofrimento psíquico ocorrem em uma amostra cujo contingente feminino é bem menor que o masculino, o que pode ser um argumento em favor de tais diferenças.

Para finalizar, é importante destacar que os achados do presente estudo apontam para as dificuldades enfrentadas pelas mulheres em seu ambiente de trabalho como fator de desgaste psíquico e, sobretudo de estresse, principalmente no ambiente policial (militar ou civil).

Mais estudos deveriam ser feitos para investigar diferenças de gênero e sofrimento psíquico, considerando-se alguns fatores já identificados como fundamentais, tais como apoio social, organização e relações no trabalho, exposição a lesões e violência no trabalho, características de personalidade, dentre outros. 


\section{Resumo}

O objetivo deste trabalho é investigar a existência de sofrimento psíquico entre policiais civis, segundo diferenças de gênero. Analisa dados de pesquisa anterior sobre condições de trabalho, saúde e qualidade de vida desses profissionais, usando métodos quantitativo e qualitativo. No presente estudo são considerados e testados alguns dados do questionário aplicado à amostra estatisticamente representativa de 2.746 (80,8\% homens e 19,2\% mulheres) policiais civis da cidade do Rio de Janeiro, Brasil, segundo a variável gênero e inserção nos distintos estratos de organização da atividade policial (setores administrativo, técnico e operacional). Apresenta um breve panorama das características sócio-econômicas, das condições de trabalho, dos problemas de saúde e da qualidade de vida desses policiais, destacando as informações em que a variável gênero aparece como fator diferenciador. $O$ Self-Reported Questionaire (SRQ-20) é o instrumento a partir do qual se investigou sofrimento psíquico. Os resultados não indicam diferença de sofrimento psíquico entre os gêneros, mas apontam para a existência de diferenças significativas em alguns itens da escala. As policiais, sobretudo as técnicas, apresentam maiores proporções em relação aos homens. Esses achados são corroborados por algumas pesquisas anteriores.

Identidade de Gênero; Estresse Psicológico; Polícia

\section{Referências}

1. Minayo MCS, Souza ER. Missão investigar: entre o ideal e a realidade de ser policial. Rio de Janeiro: Garamond; 2003.

2. Couto HA. Stress entre executivos: os 10 agentes estressantes mais freqüentes e os 13 fatores de maior potencial agressivo. In: Anais do Congresso da Associação Nacional de Medicina do Trabalho. v. 5. Florianópolis: Associação Nacional de Medicina do Trabalho; 1987. p. 747-57.

3. Patis K. Stress e isolamento social versus stress e atividade de resgate ao público: nota prévia. In: Anais do Congresso da Associação Nacional de Medicina do Trabalho. v. 5. Florianópolis: Associação Nacional de Medicina do Trabalho; 1987. p. 785-9.

4. Lipp M. Stress: conceitos básicos. In: Lipp M, organizadora. Pesquisas sobre stress no Brasil: saúde, ocupações e grupos de risco. Campinas: Papirus; 1996. p. 17-31.

5. Gershon R, Lin S, Si X. Work stress in aging police officers. J Occup Environ Med 2002; 44:160-7.

6. Hawton AC, Sakarovitch C, Simkin S, Deeks, JJ. Suicide in doctors: a study of risk according to gender, seniority and specialty in medical practitioners in England and Wales, 1979-1995 (Statistical Data Included). J Epidemiol Community Health 2001; 5:296-300.

\section{Colaboradores}

E. R. Souza, C. C. Meireles e V. T. Ferreira participaram da concepção, análise e redação do artigo. L. G. Franco participou da análise e redação do artigo. N. C. Santos realizou as análises estatísticas.

\section{Agradecimentos}

A João Paulo Costa da Veiga e Juaci Vitória Malaquias, pela cuidadosa revisão dos dados e valiosas orientações na construção das tabelas.
7. Dejours C. A loucura do trabalho: estudo de psicopatologia do trabalho. São Paulo: Cortez Editora/Oboré; 1992.

8. Glina DMR, Rocha EL, Batista ML, Mendonça MGV. Saúde mental e trabalho: uma reflexão sobre o nexo com o trabalho e o diagnóstico, com base na prática. Cad Saúde Pública 2001; 17:607-16.

9. Rocha DC. Agentes estressores presentes em um hospital psiquiátrico. In: Reunião Anual da Sociedade Brasileira para o Progresso da Ciência, Resumos. Natal: Universidade Federal do Rio Grande do Norte/Sociedade Brasileira para o Progresso da Ciência; 1998. p. 117.

10. Neto, RC, Lima, LM. Nível de estresse na Polícia Militar. Fisioter Bras 2003; 4:108-16.

11. Fernandes RCP, Silvany Neto AM, Sena GM, Leal AS, Carneiro CAP, Costa FPM. Trabalho e cárcere: um estudo com agentes penitenciários da Região metropolitana de Salvador, Brasil. Cad Saúde Pública 2002; 18:807-16.

12. Rocha LE, Debert-Ribeiro M. Trabalho, gênero e saúde: estudo comparativo sobre analistas de sistemas. Rev Saúde Pública 2001; 35:539-47.

13. Pereira CAM. Que homem é esse? O masculino em questão. In: Nolasco S, organizador. A desconstrução do masculino. Rio de Janeiro: Rocco; 1995. p. 53-8. 
14. Sloan T, Jirón RR. La desconstrucción de la masculinidad. http://www.artnet.com.br/ marko/sloan. htm (acessado em 15/Abr/2004).

15. Cecarelli PR. A masculinidade e seus avatares. Catharsis 1998; 4:10-1.

16. Santos AV. Sexualidade feminina, essa quase desconhecida [Monografia de Graduação]. Niterói: Faculdade de Psicologia, Universidade Federal Fluminense; s.d.

17. Cecchetto FR. Violência e estilos de masculinidade. Rio de Janeiro: Editora FGV; 2004.

18. Connel RW. Políticas da masculinidade. Educação e Realidade 1995; 20:185-206.

19. Vermeulen M, Mustard C. Gender differences in job strain, social support at work, and psychological distress. J Occup Health Psychol 2000; 5:428-40.

20. Calais SL, Andrade LMB, Lipp MEN. Gender and schooling differences in stress symptoms in young adults. Psicol Reflex Crit 2003; 16:257-63.

21. Fuhrer R, Stansfeld AS, Chemali J, Shipley MJ. Gender, social relations and mental health: prospective findings from an occupational cohort (Whitehall II study). Soc Sci Med 1999; 48:77-87.

22. Bergl MA, Hem E, Lou B, Haseth K, Ekeberg O. Stress in the Norwegian police service. Occup Med 2005; 55:113-20.

23. Collins PA, Gibbs ACC. Stress in police officers: a study of the origins, prevalence and severity of stress-related symptoms within a county police force. Occup Med 2003; 53:256-64.

24. Chor D, Griepe RH, Faerstein E. Medidas de rede e apoio social no estudo Pró-Saúde: pré-testes e estudo piloto. Cad Saúde Pública 2001; 17:887-96.

25. Busnelo EL, Lima B, Bertolote JM. Aspectos interculturais de classificação e diagnóstico. J Bras Psiquiatr 1983; 32:207-10.

26. Harding TW, Arango MV, Baltazar J, Climent CE, Ibrahim HHA, Ignacio LL, et al. Mental disorders in primary health care: a study of their frequency and diagnosis in four developing countries. Psychol Med 1980; 10:231-41.
27. Dhadphale R, Ellison RH, Griffin L. The frequency of psychiatric disorders among patients attending semi-urban and rural general out-patient clinics in Kenya. Br J Psychiatry 1983; 142:379-83.

28. Sen B, Wilkinson G, Mari JJ. Psychiatric morbidity in primary health care: a two-stage screening procedure in developing countries - choice of instruments and cost-effectiveness. Br J Psychiatry 1987; 151:33-8.

29. Sen B, Mari JJ. Psychiatric research instruments in the transcultural setting: experiences in India and Brazil. Soc Sci Med 1986; 23:277-81.

30. Mari JJ, Williams P. A validity study of a psychiatric screening questionnaire (SRQ-20) in primary care in the city of São Paulo. Br J Psychiatry 1986; 148:23-6

31. Busnello EL, Pereira MO, Knapp WP, Salgado CAI, Taborna JGV, Knijnik L, et al. Morbidade psiquiátrica na população urbana de Porto Alegre. J Bras Psiquiatr 1993; 42:55-60.

32. Lima RK. A polícia da cidade do Rio de Janeiro: seus dilemas e paradoxos. Rio de Janeiro: Forense; 1995

33. Ustarróz LF. Eventos estressantes, insatisfação na vida e morbidade psiquiátrica menor em Pelotas [Dissertação de Mestrado]. Pelotas: Departamento de Medicina Social, Universidade Federal de Pelotas; 1997.

34. Due P, Holstein B, Lund R, Modvig J, Avlund K. Social relations: network, support and relational strain. Soc Sci Med 1999; 48:661-73.

35. Moraes LFR, Pereira LZ, Souza KO, Guzmão LVN. Implicações do gênero na qualidade de vida e estresse no trabalho da Polícia Militar do Es tado de Minas Gerais. In: Anais do V Congresso de Ciências Humanas, Letras e Artes. Ouro Pre to/Mariana: Universidade Federal de Ouro Preto; 2001. p. 56

Recebido em 28/Jul/2005

Versão final reapresentada em 08/Mar/2006

Aprovado em 20/Abr/2006 